\title{
Exploration on the origins of thoughts of Lao $\mathrm{Zi}$
}

\author{
Xu Xinghua \\ (Journal Editorial Department, Tonghua Normal University, Jilin Tonghua 134002)
}

Key words: Lao Zi; Thoughts; Origins

\begin{abstract}
Lao $\mathrm{Zi}$ is the founder of Taoism, and his ideas have subtly influenced the Chinese civilization for thousands of years from politics, economy, philosophy, military, religion and other aspects. In many ways of original religion, "doctrine of the ancient", culture of Shang Dynasty, "Book of Songs" and the history books, this paper has explored the origins of thoughts of Lao Zi, trying to reproduce its clear context.

As the "officer of library in Zhou", after years engaging in politics, Lao Zi used the social change "Countries did not have a fixed enshrined people, and there is no fixed seats between the monarch and his subjects" in the voluminous historical texts. In the face of such dramatic changes " Alpine becomes the valley, deep valleys turns into hills", Lao $\mathrm{Zi}$ had on hard thinking to politic, society, life and many other ways. In the puzzling and searching process, Lao Zi inevitably dated from the former generation, and even further back.
\end{abstract}

\section{Lao $\mathrm{Zi}$ and primitive religion}

Primitive religion is the product for collective thinking of primitive human in the existence struggle with nature, which penetrates in all aspects of social life. Two main aspects had profound impacts on the thoughts of Lao $\mathrm{Zi}$, and one is the female worship, the other is the witch history culture.

Women worship

Ancient China's matriarchal clan almost without exception developed from matriarchal society, in which prevailed the women worship. Lao zi inherited from the perspective of women worship, mainly manifesting in his remarks about matriarch and the incisive and vivid interpretation in his book about good qualities of gentle, humility, kindness and emptiness belonging to the women. According to historical research, the matriarchal society governance was pursuing the ruling principle for loving successors, gentle and unambitious characteristics and less private desires, promoting women's feminine, amiable, quiet beauty. Lao $\mathrm{Zi}$ inherited this view of worshiping the gentle quality, and repeatedly mentioned the word "mother" in the book, then he compared the core idea of "Taoist" as the mother, and thought "Tao" was a vain parent, which was "born before the world", "origin, like sources of all things". Lao $\mathrm{Zi}$ further pointed out that "Void change is never-ending, things are growing without sound. Taoist, not be detected, has created all things, which is the root of the universal things' birth. Taoist is endless and forever, and there is not weary, not exhaustive use. ". " The root of all things" and "void change" is used to indicate the endless characteristics of Taoist that gestates all things. Lao $\mathrm{Zi}$ also proposed "Air and tranquility of mind must reach the ultimate"; "Reduce the pursuit of various desires such as wealth, prosperity and ingenuity"; "The most fragile things in the world can walk through the hardest things", using the vocabularies full of femaleness to reflect the characteristics of Taoist. American atomic physicist Capra believed that "Taoist emphasizes intuitive, women, mysterious and flexible things." So Lao $\mathrm{Zi}$ said, 'Supreme sages treat things with the inaction view and make subtle guidance to educate the people.' Taoism believes that showing soft human nature of the female most easily leads to the perfect balance between life and way." ${ }^{11]}$

Witch history culture

Since ancient times, Chu has been regarded as a wilderness, and the economy and culture are far behind central plains. The faith for witch history culture was inveterately retained, and the original 
witch history was still very popular until the warring states period, then "Song of Chu" kept a record of a large number the Chu primitive religious myths and witchcraft ceremonies. On the basis of witch history culture, due to less influenced by the music civilization of central plains, Chu culture obviously contained the tendency of individualism, which considered the transcendence of individual life, the absolute freedom of spirit and the height liberation of human as the highest ideal of life, showing a natural and unrestrained natural, romantic and exquisite cultural style. Living in Chu culture, the way of Lao $\mathrm{Zi}$ thinking way and value concept were inevitably affected. Zhang Qizhi has ever pointed out, "The civilization of Yan emperor tribe developed the Jingchu culture, which was the root of the Taoist culture." ${ }^{[2]}$ Throughout the book "Lao Zi" with the rhymes, the book has brief words, free and easy style and far-reaching conception, embodying the style of Chu culture. By proposing a series of concepts "Returning to the roots is quiet", "Reducing the pursuit of various desires such as wealth, prosperity and ingenuity" the book also reflected the way of thinking and value concept for beyond self and life, pursuing of spiritual liberation.

\section{Lao Zi and "Ancient Doctrine"}

"Zhuang Zi, World" says, "The ancient doctrine lies in it, enjoyed by Guan Yin and Lao Zi." Zhu xi pointed out, "Because Lao Zi was the historian of Zhou Dynasty, in charge of books for states and emperors, he could speak of ancient things, and people believe and appreciate him. Such as the five thousand words, he eulogized the old saying that people did not understand." That Laozi saying derived from "Ancient Doctrine" is well-founded. Lao Zi claimed to be "If one can insist the ancient doctrine, he can control all things, govern a good home and country, and become acquainted with ancient and initial conditions, so that we can understand the whole system of 'Taoist'." Therefore there are "saint say", "ancient ideas", "fighting words", "suggestions", "hearing", etc. The book "Lao $\mathrm{Zi"}$ has 81 chapters, and 22 chapters mention "the saint" of the ancient. These "saints" should be the tribal chieftains of primitive society; Be those who have great experience in governing the sage almighty; Be "owners of country" with "Supreme" who" gave birth to all things without appropriation, promoted all things, and not count on their achievements, and kept things without domination"; Be the "kings of the world" "The saints were above the people, and people did not think them burdens; Prior in people, and people did not consider them harm. The people were willing to support him without feeling tired, because he did not quarrel with the people, and no one can fight against him in the world." "Ancient doctrine" Lao Zi praised highly took "inaction" concept as the core. "'covering hands' and 'hanging clothes' existing as ancient governance, is the description to ruling way of the ancient emperor (Huangdi, Yao, Shun, etc.) and the visual description to their attitudes, and its purpose is that wise emperor make good use of worthy persons, making them perform their duties without interference of the emperor, who did nothing with ease humility and disturbances." ${ }^{[3]}$

On the basis of the combination of the ancient imperial political experience and the criterion behaving themselves from generations to generations of the ancient sages, Lao $\mathrm{Zi}$ summarized the "Taoist" theory. He thought that monarch who used the rule of "Taoist" to govern the country" could "Considering people hearts as hearts", "Treating things with the inaction view and making subtle guidance to educate the people", and complied with the inherent law of things, "Be careful d to assist the growth of everything", so as to achieve the good social effect "With principles of inaction, there is no bad things", "If I do not misbehave, people naturally have good enlightenment; if I like quiet, people are naturally honest; if I do not increase the burden to the people, people will be rich; if I am not voluptuous, people will gradually become more simple", because the saint " Afraid of being prior to people living in the world, so I will become the head of all things". 


\section{Lao Zi and Shang Dynasty culture}

"Worshiping the gentle quality" was a prominent feature of Lao Zi thought, and this view clearly derived from matriarchal society." But it was far away from Lao Zi's age after all, and it had indirect influence on Lao $\mathrm{Zi}$ through the intermediate link for Shang Dynasty society." ${ }^{[4]}$ According to textual research, Shang Dynasty society had still kept a strong custom of maternal age, and it can be seen that according to the unearthed oracle information age women's status was very high. Shang dynasty in politic women could be acted as the local governors, paying tribute to Shang emperor; In the economic fields they could own farm lands, responsible for agricultural production of the region; They could lead troops in military and station in the border; On religious custom they could participate in sacrifice, and were sacrificed after death together with men. These are found nowhere else in the later patriarchy society.

"Zhouli, Chunguan, Dabu" recorded," Master three Yi methods, the "Lianshan", the "Guizang", and the "Zhouyi", their hexagrams are eight, and the words are all 60." According to Zheng Xuan "Lianshan" was the Xia "Yi", "Guizang" was the Yin "Yi", the ancient three "Yi" had first recognized by Confucianism. The Book "Liji, Liyun" described that Confucius said, "I would like to research the Yin Taoist, which could not be completed duo to insufficient data, but I got the "Kunqian"."Kunqian" was namely "Guizang". Lao $\mathrm{Zi}$, as a philosopher slightly earlier than Confucius, with conveniences of "weeks keep hidden chamber", was likely to see "Guizang" and benefit from it. As the book of augury, "Guizang" and "Zhouyi" happened to be contrary, and the order of the sixty-four hexagrams is Kun for the first and Qian for the second. Jin Jingfang thought that Kun for the first and Qian for the second of "Guizang" was no accident, which reflected the characteristics of "close Yin Taoist", and emphasized the consanguinity and attached great importance to the mother series, prominently manifested in inheritance system. Shang dynasty reversed the son system Xia Dynasty, and started brother system, which was not simple recovery of history before Xia dynasty, but the twists and turns in progress. The ancients called the system brother "close", and the sub system is called the "honor". "close" took the mother of series seriously," and "honor" was more about the parent system. ${ }^{[5]}$ In the era of Shang Dynasty, the system of brother was its outstanding performance for emphasis on consanguinity and great importance to the mother series, and those illustrated the moment still had a survival from the matriarchal society, then the thought of Lao Zi worshiping the mother might directly root in it.

\section{Lao $\mathrm{Zi}$ and the "Book of Songs"}

"Book of Songs" is the first poetry collection in China. Zheng Zhenduo has ever said, "For all research of ancient Chinese literature, ancient social situations, and even the ancient thought, "book of Songs" should be regarded as a good data." ${ }^{[6]}$ So should study the origin of Lao Zi thought.

In "book of Songs" there are three hundred and five poetries with rhyme as style. Fifteen national songs have lyric poem end with "Xi", mainly in form of Chinese classical poem with four characters each line, showing tidy and harmonious unity. Throughout "Lao Zi", there are a lot of spaces with rhyme as same as the "book of Songs", and the former generation of scholars such as Deng Tingzhen, Liu Shipei and Zhu Zhiqian believed that the writing style of "Lao Zi" may be affected by the influence of "Book of Songs".

"Inaction" is the important concept of Lao $\mathrm{Zi}$ thought, which is not first used by Lao Zi, while appeared in the "book of Songs" according to the known literatures. "Guofeng, Wangfeng, Tuyuan" recorded, "The hares make contacts with freedom, while arrested pheasants are very miserable. In my childhood, people don't have to military service; In my adult years, all kinds of hardships had gathered." The "inaction", according to Gao Heng's explanation, should be "do nothing at leisure comfortable" [7]."In "Guofeng, Chenfeng, Zepo", "inaction" of "inaction without sleep" can be interpreted as the meaning of easy and comfortable. Although the meaning of "inaction" in the "book of Songs" can not equate with that in Lao Zi thought, it was also possible that Lao Zi drew lessons from the notion of "inaction" in the "book of Songs", and generalized abstractly and put it to 
ascend, then developed his own way of ruling a nation for "get the world by doing nothing" statecraft.

Many terms in "Lao $\mathrm{Zi"}$ are similar with that in the "book of songs", for example "Kuaifeng, Feifeng" wrote, "Who will cook the fish to eat ? I will lend him the pot. "Mao Chuan" said, "When cooking the fish with bother, the fish will be broken; When ruling people with bother, the state will collapse. Knowing how to cook the fish will know how to govern the country." Confucius "Shu" said, "Making fish and controlling people must not bother. Knowing the way to cook the fish will know the way to govern the country. The focus on governing the nation is in quiet." And Lao Zi put forward in chapter 60 famous political theory "Governing a large country is like cooking a small fish ", emphasizing the importance of without disturbing people casually. Another example is "Xiaoya Lue" contained, "Parents gave birth, comfort, upbringing, education, refuge, patient care and embrace to me. I want to repay the kindness of parents, their grace is greater than everything", and Lao Zi proposed in chapter 51 "The parents gave birth to a man, brought up him, taught him, then make him independent and mature", which was exactly the same as the former.

\section{Lao $\mathrm{Zi}$ and historical classics}

As an official historian, in good contact with historical documents and books, mastering a large number of historical knowledge, Lao $\mathrm{Zi}$ "experienced and recorded the success or failure survival way", "understood the reason of the ancient and modern combat", and further enriched and perfected the system of his thoughts.

Lao $\mathrm{Zi}$ referred to some ideas in history books directly. Such as chapter 42 "Violent persons can not control their own fate", "Yellow emperor Jinrenming" commented, "there was that idea in the ancient language, taken by Lao Zi." Or chapter 79 "Heaven treated with mortal beings equally, but often unconsciously and secretly helped good people ", which was appeared in Liu Xiang "Shuoyuan,Jinshen" citing for "Yellow emperor Jinrenming", "Book of later Han, Legend of Yuanshao" citing for "Taigongjinkui". Lao Zi also put forward in chapter 36 "To converge it, we must first expand it; To weaken it, we must first strengthen it; To abolish it, we must first lift it, To win it, we must first give it." And "Zhoushu" had ever pointed out, "To beat it, we must help it for the moment; To win it, we must give it for the time being", and the Song Dynasty Wang Yinglin thought these words in "Zhoushu" might be "Zhoushu, Yinfu" Suqin mentioned during the warring states period (seeing in chapter 36 in "Lao Zi critical interpretations ").

Some views were inherited and played, or as a main argument, or as the main theoretical basis to increase the article's critical thinking. "Shangshu,GaotaoMo "recorded," Gao Tao says, "Open-minded and prudent; Moderate and strong-minded; Humble and earnest; Talented but not sparse; Decisive in the face of chaos; Honest and modest; Simple and subtle; Upright and not reckless; Brave and trustworthy justice. "" "Soft" was as necessary condition for" independent". "Hong Fan" said again, "three virtues, 'the integrity, the strength, and the softness... deep and latent with intrinsic strength."' Lao Zi inherited the ideas of opposite between firm and soft, and played the role of "using softness against strength", then claimed "the way of the weak ", finally proposed important propositions to overcome the strong. Once more, "Shangshu, Zhouguan" recorded, "We should control the social order of the country and protect national security when the disturbances had not occurred." Lao $\mathrm{Zi}$ in chapter 64extended it as thoughts of preparing for a rainy day "Work to begin before it occurred; Govern nation to make early preparations before disaster has not yet produced".

In a word, the thought of Lao $\mathrm{Zi}$ has the extremely profound origin, which covered from the matriarchal society in ancient times" Politic is chaotic, while people are faithful honest" to the Spring and Autumn troubled period " In order to fight for land, killed people covered wilderness. In order to fight for city, the citywas full of people who were killed", from the remote Jingchu land to the central plains with highly developed rites and music and civilization, the politics of ancient times in the legend to the laws in ancient Shang Dynasty with political history, and you can see the trace of the thought origin of Lao $\mathrm{Zi}$. 


\section{References}

[1] [US] Capra. Way of Physics [G]// Compiled by Guangeng.. Sichuan People's Publishing House, 1983.

[2] Fang Guanghua. Summary on "Second Seminar of Lao Zi thought"[J]. Chinese Culture, 1994(1).

[3] Wang Zhongjiang Historical Origin of Governance of Lao Zi - With the association of "Rule by Covering Hands " and "Governance with Inaction" as the center [J] History of Chinese Philosophy, 2002 (3).

[4] Ai Qi. Influence of Shang Dynasty Culture on Lao Zi thought [J]. Yindu Journal, 1997(2).

[5] Kang Xuewei. Research on Filial Duty of Pre-qin Period[M]. Jilin People's Publishing House, 2000.

[6] Zheng Zhenduo. Thought on "Mao Poetic preface" [M]// Shanghai Ancient Books Publishing House, 1982.

[7] Gao Heng. Present Note of Book of Songs[M]. Shanghai Ancient Books Publishing House, 1980. 